\title{
Prevailing Need for Sex Education in the Indian Education Setting
}

\section{Mithi Shukla*, Gunjan Mishra and Tarannum Sarwar Dani}

\author{
Amity University Chhattisgarh \\ E-mail Addresses: mithishukla963@gmail.com; gmishra@rpr.amity.edu; tsdani@rpr.amity.edu \\ *Corresponding Author E-mail: Mithi Shukla; mithishukla963@gmail.com
}

\begin{abstract}
Sex is a very sensitive and personal topic. Public discussions on sexual matters is considered as a shameful experience, especially in India. Most of us do not talk openly about the topic in front of our elders; while some of the others, don't even know about the whole concept of the sexual intercourse. Talking about sex is becoming more normalized because of the technological interventions and also because more people are becoming aware of it. Sex Education have actually paid a very important role behind it. The real purpose behind sex education is the transfiguration of a male child into their manhood and female child into their womanhood. Sex education provides knowledge on physical, social, moral, behavioral and psychological changes and developments during puberty. It teaches the adolescents about their roles, responsibilities and attitudes in family and society. Due to increasing incidents of sexually transmitted diseases like AIDS, sexual crimes and teenage pregnancies, there is a need to impart sex education among adolescents. Also, not just biological specifics, sex education can also help regulate teen emotions and values towards intra personal and interpersonal relationships in the society. This paper aims at informing about the necessity of Sex Education in the Indian context; and why its lack is detrimental in the growth of adolescents.
\end{abstract}

Keywords: sex education; Indian culture; sexually transmitted diseases; curricula; comprehensive sex education

\section{INTRODUCTION}

Sexual Health is a very important domain of health fundamentals. Sex education is defined as a broad program that not only talks about the process of coitus, but also it builds a strong lifelong foundation of importance of sexual health by acquiring information about one's self identity, social relationships, intimacy, emotional wellbeing, need for protection and also sexually transmitted diseases and how to prevent them. It also informs about the curb of the intercourse and when it becomes violent.

Primarily, during adolescence (13-19 years) its provision is a crucial preventative tool, as it is the time when young people experience developmental changes in their body. This affects both their physic and psyche. Added to this, there is often an impulsiveness to indulge in actions that are forbidden and risky combined with the inadequacy of wisdom.

The complex emotional state and the need to find self-identity, around the stigma formed by the society makes it very challenging for the adolescents to attain the knowledge they need. The existence of these stigmas handicaps the adolescents' health programs. These results in negative health outcomes such as early and closely spaced pregnancy, unsafe abortions, STDs, HIV/AIDS, and sexual violence, the rates of which are already disturbingly increasing.

The major objectives of sex education can be broadly described as follows [1]:

1. To develop emotionally stable adolescents who feel sufficiently secure and adequate to make decisions regarding their conduct without being carried away by their emotions.

2. To provide sound knowledge not only of physical aspects of sexual behavior but also its psychological and sociological aspects; so that sexual experience will be viewed as a part of the total personality of the individual, and not a sort of taboo.

3. To develop attitudes and standards of conduct which will ensure that adolescents will determine their sexual and other behavior by considering its long-range effects on their own personal development, of other individuals and welfare of society as a whole.

Adolescents form a significant population of India (about 243 million). They are a rich human resource. Therefore, maintaining and providing required health care to adolescents will go a long way in raising health status of the society. Adolescents show a high degree of vulnerability to HIV/AIDS and other sexually transmitted infections. Health of adolescent girls, in particular, have intergenerational effect [2].

In addition to this, adolescents also develop skills like communication, listening, decision making, negotiation, empathy, advice giving and helping, through sex education. 


\section{INDIAN CULTURE AND SEXUALITY}

Sexual taboos have their root in cultural beliefs and have important indication on the sexual health and morbidity. Culture defines what a person should believe in, how to behave and how openly can they discuss the matters of sexuality. Conservative societies forbid these kinds of discussions. Many societies in India still hold misconceptions and myths about menstruation and masturbation. Elders feel reluctant to educate children on the matters of bodily changes. And teachers too feel uncomfortable discussing about these topics to their students.

India is one of the oldest cultures to study sexuality and imparting its information in the form of art and literatures. But with foreign invasion later, much of the literature went missing and people lost their touch with the knowledge about sexuality. Gradually, new norms were set. Till date, Indian societies are ridden from talking about the matters of menstruation, masturbation and coitus. There is no provision for adolescents to understand about these things.

A recent study found that only one third of rural girls were told about the menstruation by their mothers and only one fourth were explained the reason behind it [3].

In one study, it was found that friends were the source of information about sexual intercourse for $75 \%$ of the young adults whereas for $50 \%$, it was pornography films and books. These sources, as is known, are not very reliable and hardly gives information about relationship building and sexual safety ${ }^{[4]}$.

In a recent study on the upper middle-class adolescents of Mumbai, it was found that they still follow traditional norms and believe that they should wait until after they become adults before being sexually active [5].

Another study assessed the percentage of sexuality among Indian urban school adolescents. The rate of having sexual contact was $30.08 \%$ for boys and $17.18 \%$ for girls; and around $6 \%$ boys and $1 \%$ girls reported having had sexual intercourse [6].

Another study found that adolescent population had first encounter with sexual experience at the age of 15-24 years [7].

\section{ISSUES FACED BY WOMEN IN INDIA ON THE TOPIC OF SEXUALITY}

$45 \%$ of women in India marry before the age of 18 and $22 \%$ of them give birth to their first child even before they attain the legal age for marriage [8]. This has its roots in the poor education of the girl child and also the neglect and burden felt by the parents.

Modern contraceptive usage is badly low ranging from a mere $12 \%$ in Delhi to $2 \%$ in Bihar in the age group of $15-16$ years. This is further complicated by the rising causes of HIV/AIDS with the adolescent and young population comprising $34 \%$ of the total AIDS patients [1].

The situation is alarming when it comes to statistics of child sex abuse in India. In a study on child sex abuse by the Ministry of Social Justice and Empowerment, it was found that approximately $53 \%$ of male and $47 \%$ of adolescent females were victims of sex abuse [9].

In 2019, India recorded an average of 87 rape cases daily; and overall 4,05,861 cases of crime against women occurred during the year, a rise of over $7 \%$ from 2018, the latest government data released on September 29, 2020. National Crime Records Bureau showed that the majority of these cases under Indian Penal Code were registered under 'cruelty by husband or his relatives' (30.9\%) followed by 'Assault on women with intent to outrage her modesty' (21.8\%) and 'kidnapping and abduction of women' (17.9\%) [10].

\section{CURRICULA}

The National Council for Educational Research and Training (NCERT) has curriculum including sex education in schools since 1993 in India [11].

In 1994, at United Nations International Conference on Population and Development (ICPD) and its Five-Year Review member states of the UN including India declared the Sexual and Reproductive Rights (SRRs) of adolescents and young people. In order for adolescents and young people to freely make informed decisions on all matters relating to their sexuality and reproduction, they require Comprehensive Sexual Education (CSE). Therefore, government of India is obliged to provide free and compulsory CSE for adolescents and young people.

However, a curriculum for sex education was finally introduced in 2007 under 'Adolescent Education Program' which was created by the collaboration of National AIDs Control Organization (NACO) and UNICEF [11]. But since several states protested against including sex education in the school curriculum, the program was withdrawn.

\section{NEED OF THE HOUR - COMPREHENSIVE SEX EDUCATION}

Comprehensive sex education includes all the educational measures which centers around sex. Evidence shows that a combination of CSE and access to birth control appears to decrease the rates of unwanted pregnancies among teenagers. A comparison between comprehensive sex education programs with abstinence-only programs found that abstinence-only programs did not reduce the probability of pregnancy, but rather may have increased it. Whereas, syllabus that provides accurate information about condoms and contraceptives can lead to reduction in the risky behaviors reported by adolescents, as well as reductions in unintended pregnancies and STDs.

CSE enables adolescents to make informed decisions when it comes to their sexuality and health. These programs also help develop life skills and develop responsible mature behavior in young people who can understand about human rights, gender differences, sexual choices, etc. 
Studies have consistently shown the effectiveness of CSE. Researchers have found that sex education which provides accurate, complete, and age appropriate information on human sexuality including risk-reduction strategies and contraception, helps young people take measures to protect their health, including delaying sex, using condoms or contraceptives, and being monogamous.

\section{HOW CAN MENTAL HEALTH PROFESSIONALS HELP IN SPREADING AWARENESS ABOUT SEX EDUCATION?}

Mental Health Professionals play an important role in discussing sexuality as part of their daily clinical practices. They come across with people who face problems with sexuality, relationships and also who have faced traumatic sexual incident. Childhood sexual abuses, rape, violent sexual intercourse, masturbation and even pregnancy are well documented risk factors for development of depression, personality disorders and schizophrenia in later life and are linked with adjustment disorders, anxiety disorders and post - traumatic disorders and suicidal symptoms.

Additionally, people with alternate sexualities and gender incongruence can go through a lot of difficulties in adjusting to these differences and stigma of the society. LGBTQ society already goes through various societal stigmas as well as selfidentity confusion. And with no or little imparting of sex education they are even more confused than ever. This worsens the mental health of a person.

Mental Health Professional's role is to advocate for appropriate sex education. Their roles are collaborative with parents, educators, civil societies and government bodies. They can contribute in various ways but particularly in assisting with the development of a curriculum that integrates physiological and biological information linked with the psychological and developmental elements. Another role of Mental Health Professionals is to research ways to collect data on the current status and population needs for sex education and to evaluate programs for sex education.

\section{CONCLUSION}

Health is a basic human right, and so is sexual health. Adolescents have the right to lead a healthy lifestyle. As they grow, they want to become independent and responsible and make their own decisions. The balance between responsibility and rights is crucial for the development so that there is no emotions of guilt and regret in the future. But responsibility is a twoway street. So, society needs to provide them with correct and complete information and the young people must understand carefully.

Also, any states that aims to target maximum audience cannot do so only by formal educational schemes. There has to be mental health groups, NGOs, and Community Programs to target audience through both formal and informal way of communication.

In the light of this paper, it can be known that India is obliged to provide comprehensive sexuality education in all public and private schools and that the denial of such education to children adolescents and young people is a violation of India's commitments under international law. Arguments on culture, morality or stigmas are invalid in this context. Further, the provision of age - appropriate comprehensive education on sexuality and HIV/AIDS can also have significant consequences in dealing with sexual abuse and in reducing the spread of sexually transmitted diseases.

\section{REFERENCES}

[1] Garg N., 2015, Sex Education to Indian Adolescents - Need of the Hour, IOSR Journal of Humanities and Social Science, Vol. 20, Issue 1, pp 59-61, DOI - 10.9790/0837-20115961.

[2] Haberland N. and Rogow D., 2014, Sexuality Education - Emerging Trends in Evidence and Practice, Journal of Adolescent Health, Vol. 56, S15-S21.

[3] Kotecha P.V., Patel S., Baxi R.K., Mujumdar V.S., Misra S., Modi E., et al., 2009, Reproductive Health Awareness among Rural School going Adolescents of Vadodara district, Indian J Sex Transm Dis, Vol. 30, pp 94-99.

[4] Nawsa S. and Marfatia Y.S., 2010, Adolescent HIV/AIDS: Issues and Challenges, Indian J Sex Transm Dis and AIDS, Vol. 31, No. 1, pp 1-10.

[5] Selvan M.S., Ross M.W., Nagaraj S., Etzel C.J., and Shete S., 2005, Perception among Upper Middle Class Adolescents in Bombay regarding Sex and Sexuality, Indian J Public Health, Vol. 49, No. 4, pp 250-251.

[6] Ramadugu S., Rayali V., Srivastava K., Bhat P.S. and Prakash J., 2011, Understanding Sexuality Among Indian Urban School Adolescents, Ind Psychiatry J, Vol. 20, pp 49-55.

[7] Reddy G.D., Narayana P.E. and Sreedharan A.K., 1983, A Report on Urban (Madras) College Student's Attitudes Towards Sex.

[8] Moore A.M., Singh S., Ram U., Remez L. and Audam S., 2009, Adolescent Marriage and Childbearing in India: Current Situation and Recent Trends, Guttmacher Institute, New York.

[9] Ministry of Women and Child Development, Government of India, 2007, Study on Child Abuse.

[10] India has Highest Number of Children, Teens with HIV in South Asia: Report, 2018, Business Standard.

[11] National Population Education Project, Department of Education in Social Sciences \& Humanities, National Council of Educational Research and Training, 2010, Adolescence Education Programme: Training and Resource Material, NCERT, New Delhi 
[12] Sex Education: Why India should go all the way, Times of India, 2016.

[13] Advocates for Youth, Sexuality Education: Building an evidence and rights-based approach to healthy decisionmaking.

[14] Alford S., et a, 2008, Science and Success: Sex Education and Other Programs that work to Prevent Teen Pregnancy, HIV and Sexually Transmitted Infections, $2^{\text {nd }}$ edition, Washington DC, Advocates for Youth. (CSE paragraph and conclusion)

[15] Sood N. and Suman P., On the Lack of Comprehensive Sexuality Education in India, Youth Coalition for Sexual and Reproductive Rights (YCSRR).

[16] Ismail S., Shajahan A., Tss R. and Wylie K., 2015, Adolescent Sex Education in India: Current Perspectives, Indian Journal of Psychiatry, Vol. 57, No. 4, pp 333-337, DOI - 10.4130/0019-5545.171843.

[17] WHO, Defining Sexual Health, Geneva, 2006.

[18] Kar S.K., Singh A.P. Kar S.K., Prakash O. and Tripathi A., 2017, Sex Education in India: Why, What, When, Where, Whom? Indian Institute of Sexology Bhubaneshwar.

[19] Khanna A. and Khanna P., 2016, Adolescent Sex Education - Indian Scenario, Indian Institute of Sexology Bhubaneshwar.

[20] Gupta B. and Shukla R., 2016, Issues Related to Adolescent Sexuality and Role of Socio - Cultural Factors in Sexual Behaviors among Adolescents in India, Indian Institute of Sexology Bhubaneshwar.

[21] Krishnan V. and Sarkar S., 2016, Sex Education: Role of Mental Health Professionals in India, Indian Institute of Sexology Bhubaneshwar.

[22] WHO, 2011, The Sexual and Reproductive Health of Younger Adolescents Research Issues in Developing Countries: Background paper for a consultation, Geneva.

[23] Andrew G., Patel V. and Ramakrishna J., 2003, Sex, Studies or Strife? What to Integrate in Adolescent Health Services, Reprod Health Matters, Vol. 11, No. 21, pp 120-129.

[24] Burton R. and Arbuthnot F.F., 1984, Translated 'The Kamasutra of Vatsyayana', New York, pp 223.

[25] Jahnavi G. and Patra S.R., 2009, Awareness regarding Contraception and Population Control among School going Adolescents, East Afr. J. Public Health, Vol. 6, pp 226-228. 